Utah State University

DigitalCommons@USU

$1-1-1999$

\title{
An Overview of the SABER Experiment and Preliminary Calibration Results
}

\author{
J. M. Russell III \\ M. G. Mlynczak \\ L. L. Gordley \\ J. Tansock \\ R. Esplin
}

Follow this and additional works at: https://digitalcommons.usu.edu/sdl_pubs

\section{Recommended Citation}

Russell, J. M. III; Mlynczak, M. G.; Gordley, L. L.; Tansock, J.; and Esplin, R., "An Overview of the SABER Experiment and Preliminary Calibration Results" (1999). Space Dynamics Lab Publications. Paper 114. https://digitalcommons.usu.edu/sdl_pubs/114

This Article is brought to you for free and open access by the Space Dynamics Lab at DigitalCommons@USU. It has been accepted for inclusion in Space Dynamics Lab Publications by an authorized administrator of DigitalCommons@USU. For more information, please contact digitalcommons@usu.edu.

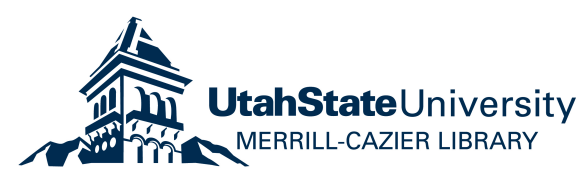




\title{
An overview of the SABER experiment and preliminary calibration results
}

\author{
J. M. Russell $\mathrm{III}^{1 *}$, M. G. Mlynczak ${ }^{2}$, L. L. Gordley ${ }^{3}$, J. Tansock ${ }^{4}$, and R. Esplin ${ }^{4}$ \\ ${ }^{1}$ Center for Atmospheric Sciences, Hampton University, Hampton, Virginia 23668 \\ ${ }^{2}$ NASA, Langley Research Center, Hampton, Virginia 23681 \\ ${ }^{3}$ GATS, Inc., 11864 Cannon Blvd., Suite 101, Newport News, Virginia 23606 \\ ${ }^{4}$ Space Dynamics Laboratory, Utah State University, 1695 North Research \\ Park Way, North Logan, Utah 84341-1947
}

\begin{abstract}
The Sounding of the Atmosphere using Broadband Emission Radiometry (SABER) experiment is one of four experiments that will fly on the Thermosphere, Ionosphere, Mesosphere, Energetics, and Dynamics (TIMED) mission to be launched in May, 2000. The primary science goal of SABER is to achieve major advances in understanding the structure, energetics, chemistry, and dynamics, in the atmospheric region extending from $60 \mathrm{~km}$ to $180 \mathrm{~km}$ altitude. This will be accomplished using the space flight proven experiment approach of spectral broadband limb emission radiometry. SABER will scan the horizon in 10 selected bands ranging from $1.27 \mu \mathrm{m}$ to $17 \mu \mathrm{m}$ wavelength. The observed vertical horizon emission profiles will be processed on the ground to provide vertical profiles with $2 \mathrm{~km}$ altitude resolution, of temperature, $\mathrm{O}_{3}, \mathrm{H}_{2} \mathrm{O}$, and $\mathrm{CO}_{2}$; volume emission rates due to $\mathrm{O}_{2}\left({ }^{1} \Delta\right), \mathrm{OH}(v=3,4,5), \mathrm{OH}(v=7,8,9)$, and NO; key atmospheric cooling rates, solar heating rates, chemical heating rates, airglow losses; geostrophic winds, atomic oxygen and atomic hydrogen. Measurements will be made both night and day over the latitude range from the southern to northern polar regions. The SABER instrument uses an on-axis Cassegrain design with a clam shell reimager. Preliminary test and calibration results show excellent radiometric performance.
\end{abstract}

Keywords: SABER, TIMED, satellite, remote sensing, mesosphere, thermosphere, temperature, ozone, non-LTE

\section{SABER SCIENTIFIC GOALS AND OBJECTIVES}

The overall scientific goal of the SABER experiment is to explore the mesosphere and lower thermosphere on a global scale and achieve a major improvement in understanding of the fundamental processes governing the structure, energetics, chemistry, dynamics, and transport of the atmospheric region extending from $60 \mathrm{~km}$ to $180 \mathrm{~km}^{1-2}$. This altitude range is essentially unexplored on a global scale because of the difficulty in sounding the region from orbit using in-situ methods and because of past emphasis of remote sensing experiments on the stratosphere and troposphere. SABER is one of four experiments on NASA's TIMED mission scheduled to be launched in May, 2000 by a Delta II rocket into a $74.1^{\circ} \pm 0.1^{\circ}$ inclined, $625 \pm 25 \mathrm{~km}$ circular orbit. The observed vertical horizon radiance profiles measured in broad spectral bands over the $1.27 \mu \mathrm{m}$ to $17 \mu \mathrm{m}$ range will be processed on the ground to obtain vertical profiles with $2 \mathrm{~km}$ altitude resolution, of temperature, density, $\mathrm{O}_{3}, \mathrm{H}_{2} \mathrm{O}$, and $\mathrm{CO}_{2}$ mixing ratios and volume emission rates due to $\mathrm{O}_{2}\left({ }^{1} \Delta\right)$ at $\left.1.27 \mu \mathrm{m}, \mathrm{OH}(v=3,4,5)\right]$ at $1.6 \mu \mathrm{m}, \mathrm{OH}(v=7,8,9)$ at $2.1 \mu \mathrm{m}$ and $\mathrm{NO}$ at $5.3 \mu \mathrm{m}$. The emissions will additionally be used to: determine atmospheric cooling rates, solar heating rates, chemical heating rates, and airglow losses; infer geostrophic winds; and retrieve atomic hydrogen and atomic oxygen, the latter inferred four different ways using only SABER observations. The experiment will also advance a key area of radiative transfer research because it will provide

* Correspondence: Email: jmr@ @amptonu.edu; Telephone: 757-728-6893; Fax: 757-727-5090 
high signal-to-noise $(\mathrm{S} / \mathrm{N})$ vertical radiance profiles in multiple spectral bands in an atmospheric region where the population densities of atmospheric molecules are governed by collisions, radiation, and chemical reactions, as opposed to being dominated solely by collisions as in the case at lower altitudes. This condition, referred to as non-local thermodynamic equilibrium or NLTE, has a significant impact on physical and chemical processes occurring in the atmosphere. Measurements will be made continuously both night and day over the latitude range from the southern to northern polar regions depending on the spacecraft yaw cycle. Some specific scientific objectives of SABER are to:

- Study the mesosphere and lower thermosphere structure including its seasonal, latitudinal and temporal variations.

- Investigate the energetics and distribution of radiatively active species in the NLTE environment to understand the relative importance of radiative, chemical, and dynamical sources and sinks of energy.

- Analyze the $\mathrm{O}_{\mathrm{y}}$ and $\mathrm{HO}_{\mathrm{y}}$ chemistry and its coupling with energetics and dynamics.

- Conduct studies of dynamics and transport and their role in the energy budget.

- Develop climatologies of key atmospheric parameters in the TIMED core region from 60 to $130 \mathrm{~km}$.

\section{SABER Experiment Approach and Key Features}

The SABER measurement approach is limb emission sounding. This method was selected because of its inherent advantages that enable measurements to be made of very tenuous, but key gases in the upper mesosphere and thermosphere and in view of its demonstrated spaceflight heritage. This heritage includes the Nimbus-7 LIMS $^{3-4}$ and SAMS experiments, the Space Shuttle CIRRIS and ATMOS, the UARS HALOE, CLAES, MLS and ISAMS experiments, and SME. The limb is scanned vertically by a 10-channel broadband radiometer operating in the near to mid-infrared from $1.27 \mu \mathrm{m}$ to $17 \mu \mathrm{m}\left(7865 \mathrm{~cm}^{-1}\right.$ to $\left.650 \mathrm{~cm}^{-1}\right)$ over the altitude range from $400 \mathrm{~km}$ to below the hard Earth surface. Radiances are measured as a function of tangent height, $\mathrm{H}_{0}$, which is the altitude of the point of closest approach of an emission ray path to the Earth surface (Fig. 1). The measured radiance $\mathrm{N}\left(\mathrm{H}_{0}\right)$ depends on the source function $J_{v}$ which is a function of wavenumber $v$ and distance along the line-of-site $x$. Under NLTE conditions, $J_{v}$ is determined by the relative populations of the upper and lower states of the observed transitions, which in turn depend on the relative importance of collisional, radiative and chemical excitation and loss processes. Transmission depends on $v$, mixing ratio $q$, temperature, $T$ and pressure, P. NLTE processes must also be considered in calculating $\tau$. The radiances are mathematically inverted or other processing methods are applied on the ground, to obtain a host of data products described later. The standard limb remote sensing approach is used ${ }^{3-4}$. Radiance is measured in a spectral band for which $q$ is known, e.g. $\mathrm{CO}_{2}$, to infer the temperature, and then radiances measured in other bands, e.g. $\mathrm{H}_{2} \mathrm{O}$, are used to

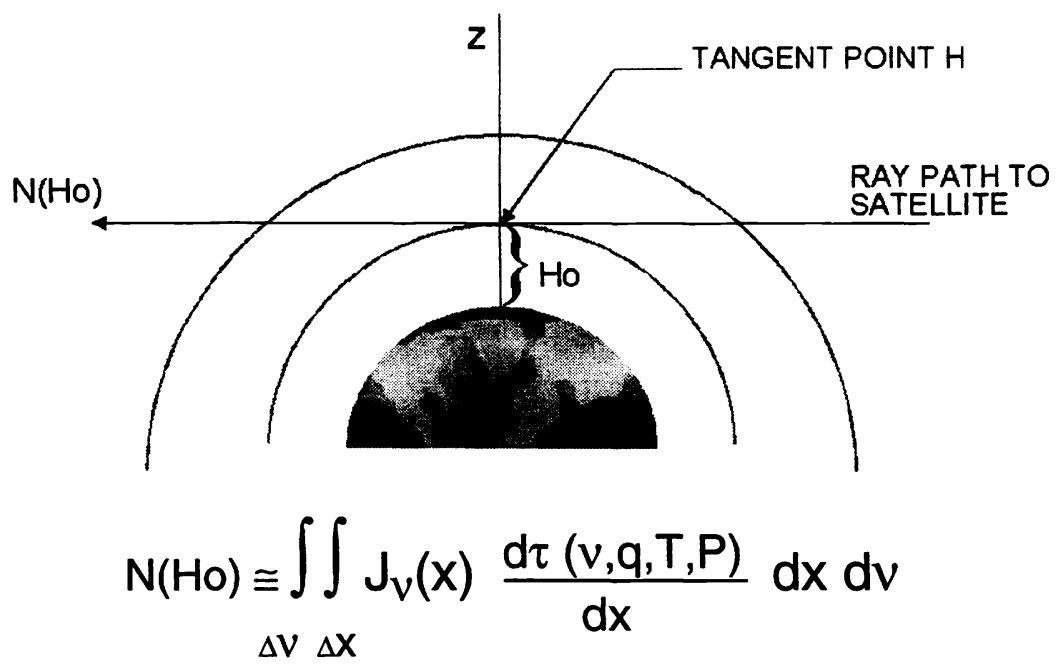

Fig 1. SABER Experiment Approach 
infer e.g. $\mathrm{q}\left(\mathrm{H}_{2} \mathrm{O}\right)$. The limb emission technique has the following distinct advantages over nadir sounders for observing atmospheric trace gases:

- Higher gas column density occurs in the field of view (30 to 60 times that of a nadir view) giving larger emission signals and enabling measurement of more tenuous gases.

- Higher vertical resolution ( $2 \mathrm{~km}$ compared to $10-15 \mathrm{~km}$ ) can be obtained because of the limb geometry and the exponential fall of density with altitude that causes most of the limb path emission to arise at just above the tangent altitude. A nadir-viewing instrument cannot observe the thermal structure and emission signatures with sufficient vertical resolution to meet the TIMED science objectives.

- Cold space is the observed background giving minimal background signal (compared to that from the warm, heterogeneous Earth surface) and making retrieval of data more simple than for a nadir experiment.

Because the experiment observes emitted energy, it has the capability to continuously sound the atmosphere both night and day permitting diurnal change and polar night studies to be conducted with daily global scale coverage. Another key experiment feature is the autonomous pressure registration and automatic correction for spacecraft motion performed in ground processing using two wide and one narrow band $\mathrm{CO}_{2}$ channel $\left(\mathrm{CO}_{2} \mathrm{~W}\right.$ and $\left.\mathrm{CO}_{2} \mathrm{~N}\right)$ centered in the $15 \mu \mathrm{m}$ band. The instrument employs state-of-the-art mechanical cooling of the detector focal plane array to $75 \mathrm{~K}$ in order to achieve high radiometric sensitivity, operational flexibility, and long experiment life. An in-flight calibration system is incorporated to provide high long-term accuracy. A summary of SABER measurements and applications is given in Table 1. As noted above, most SABER measurements will be made under NLTE conditions requiring new, state-of-the art, radiance calculation codes that will be used for geophysical parameter retrieval. Significant progress has been made by the SABER science team towards meeting this requirement and key kinetic and spectroscopic parameter accuracies have been specified ${ }^{5-13}$. Also, while we will not discuss retrieval algorithm development here, we note that substantial progress has been made. Currently we have NLTE prototype software in place for all routine products including an operational retrieval for kinetic temperature under NLTE conditions.

Table 1. SABER Measurements and Applications

\begin{tabular}{|c|c|c|c|}
\hline Parameter & $\begin{array}{l}\text { Wavelength } \\
(\mu \mathrm{m})\end{array}$ & Application & $\begin{array}{l}\text { Altitude Range } \\
(\mathbf{k m})\end{array}$ \\
\hline $\mathrm{CO}_{2}$ & 14.9 and 15.0 & $T$, density, IR cooling rates, $P(Z)$, non-LTE & $10-130$ \\
\hline $\mathrm{O}_{3}$ & 9.3 & $\begin{array}{l}\mathrm{O}_{3} \text { conc., cooling rates, solar heating, chemistry } \\
\text { inference of }[\mathrm{O}] \text { and }[\mathrm{H}] \text {, and dynamics studies }\end{array}$ & $15-105$ \\
\hline $\mathrm{O}_{2}\left({ }^{1} \Delta\right)$ & 1.27 & $\begin{array}{l}\mathrm{O}_{3} \text { conc.(day), inferred }[\mathrm{O}] \text { at night, energy loss for } \\
\text { solar heating efficiency }\end{array}$ & $50-105$ \\
\hline $\mathrm{CO}_{2}$ & 4.3 & $\mathrm{CO}_{2}$ conc.; mesosphere solar heating; tracer & $85-150$ \\
\hline $\mathrm{OH}(v)$ & 2.1 and 1.6 & $\begin{array}{l}\mathrm{HO}_{\mathrm{y}} \text { chem., chemical heat source, dynamics, inference } \\
\text { of }[\mathrm{O}] \text { and }[\mathrm{H}], \text { PMC studies }\end{array}$ & $80-100$ \\
\hline NO & 5.3 & Thermosphere cooling, $\mathrm{NO}_{\mathrm{x}}$ chemistry & $90-180$ \\
\hline $\mathrm{H}_{2} \mathrm{O}$ & 6.9 & $\mathrm{HO}_{\text {y }}$ source gas, dynamical tracer & $15-80$ \\
\hline
\end{tabular}




\section{Instrument Overview}

The SABER instrument ${ }^{14}$, under development at the Utah State University, Space Dynamics Laboratory (SDL) is shown in a cut-away view in Fig. 2 and in block diagram form in Fig. 3. A photograph of the actual flight hardware is shown in Fig. 4. The instrument telescope is a Cassegrain design with a picket-fence tuning fork chopper at the first focus, and a clam shell reimager to focus the image on the focal plane. The telescope has been designed to reject stray light from the Earth and atmosphere outside the instrument instantaneous field-of-view (IFOV). The baffle assembly contains a single axis scan mirror that permits the $2 \mathrm{~km}$ vertical IFOV of each detector to be scanned from below the hard Earth to a $400 \mathrm{~km}$ tangent height. Accurate vertical registration of the tangent height of measurements in the atmosphere is achieved by analysis of data from the $15.0 \mu \mathrm{m} \mathrm{CO}_{2}$ channels. The telescope and baffle assembly is cooled to $240 \mathrm{~K}$ by a dedicated radiator. The focal plane assembly, consisting of a filter array, a detector array, and a Lyot stop, is cooled to $75 \mathrm{~K}$ by a miniature "pulse tube" cryogenic refrigerator. The detector array contains discrete $\mathrm{HgCdTe}, \mathrm{InSb}$, and $\mathrm{InGaAs}$ detectors. The conductive heat load on the refrigerator is minimized by a Kevlar support system that thermally isolates the focal plane assembly from the telescope. The telescope is supported and thermally isolated from the instrument base plate by a glass composite structure. The cryogenic refrigerator and electronics heat loads are dissipated to space by the plate radiator. Instrument responsivity drifts due to changes in telescope and focal plane base temperatures as well as other causes are corrected by a "full field" inflight calibration system. The instrument measures $77 \times 104 \times 63 \mathrm{~cm}$, it has a mass of $75 \mathrm{~kg}$, it consumes 77 watts average power, and the data rate is $4 \mathrm{kbs}$.

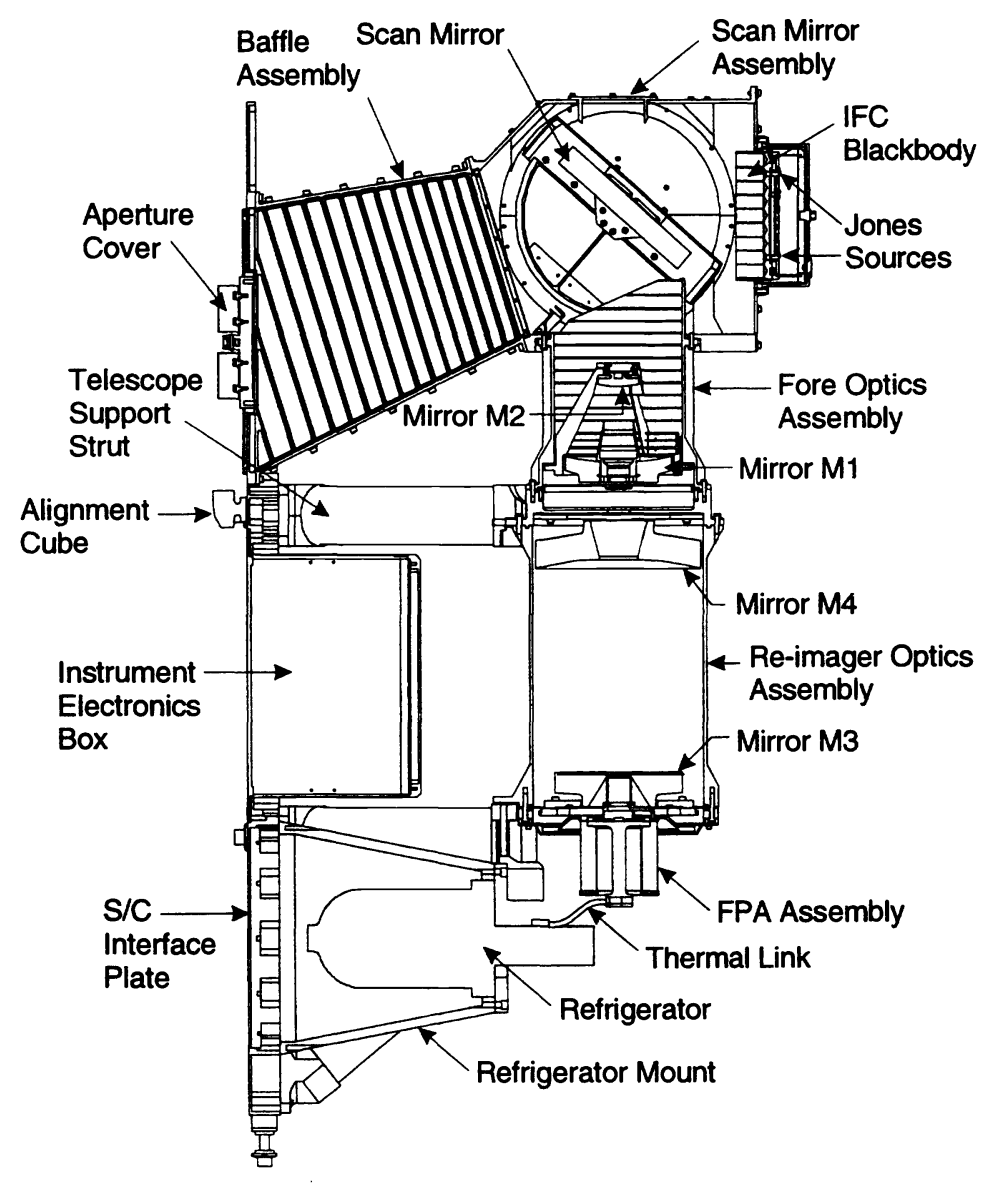

Fig. 2 SABER Instrument Cut-Away View 


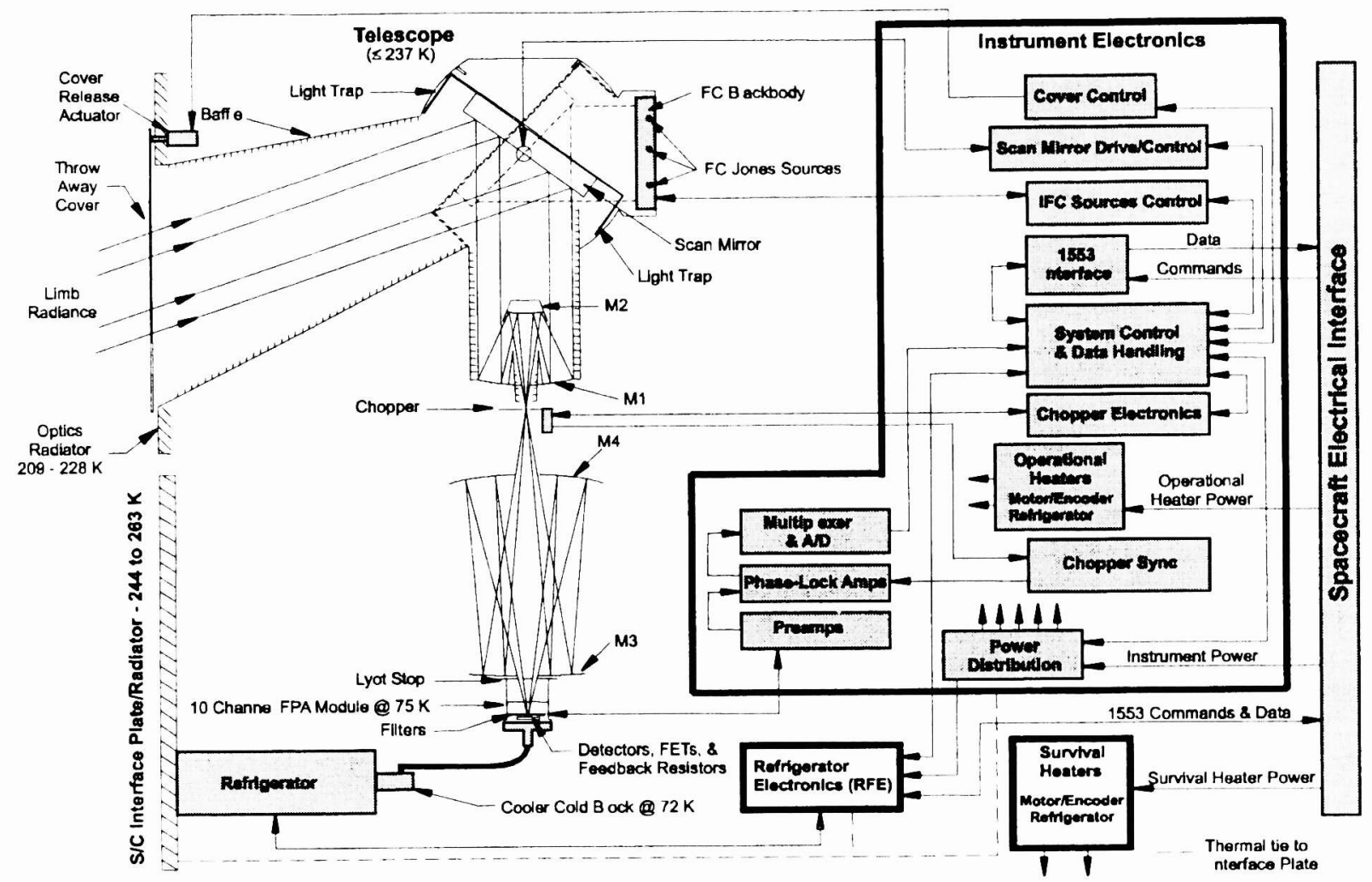

Fig. 3 SABER Functional Block Diagram

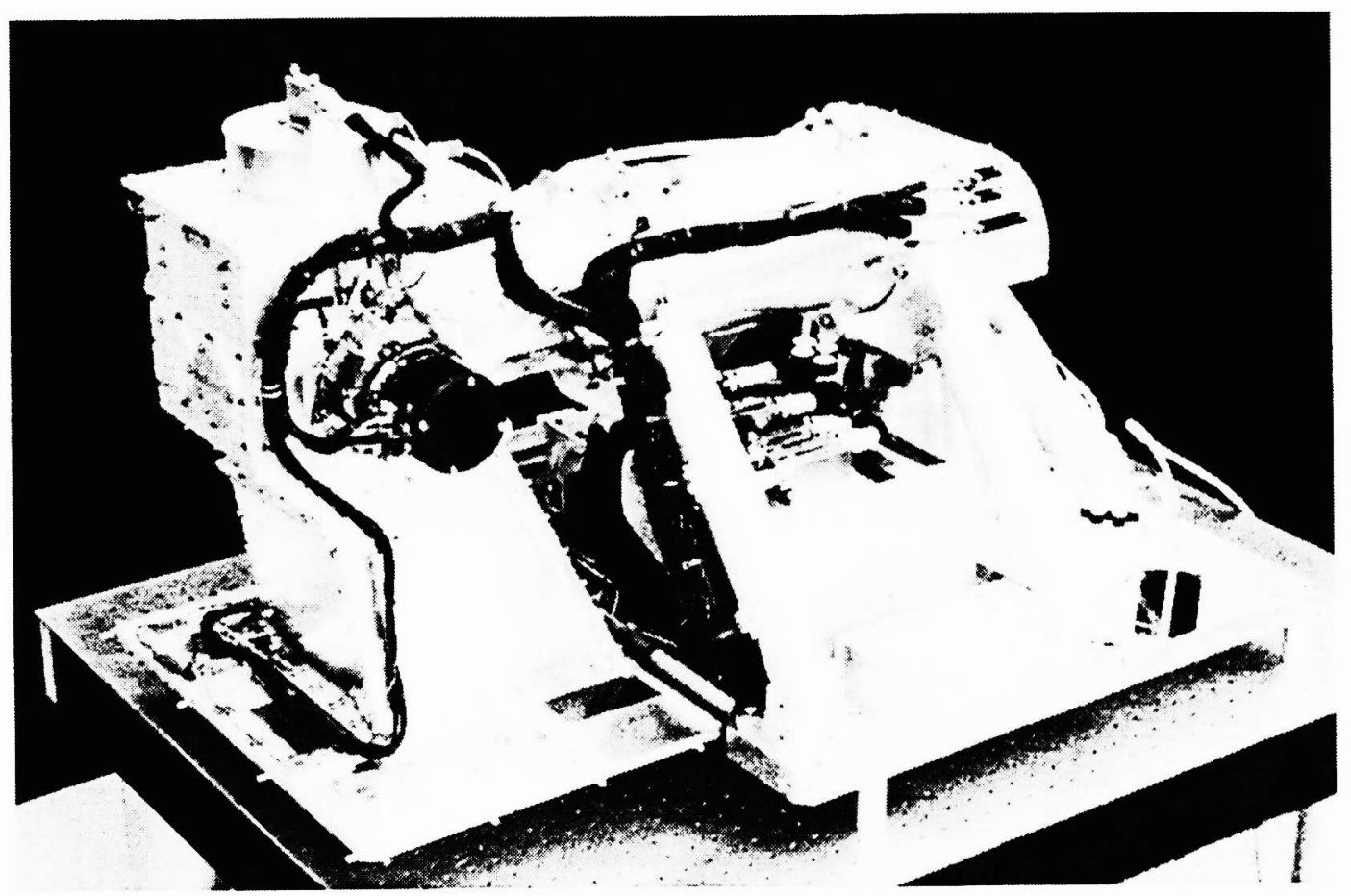

Fig. 4 SABER Flight Hardware 


\section{SABER Data Products}

The series of SABER data products will include Level 0: Unprocessed signals in counts; Level 1A: signals in counts, time referenced and tagged with ancillary data; Level 1B: Calibrated and spacecraft motion corrected radiances ready for limb retrieval applications; Level 2A: Observed geophysical parameters - Routine products; Level 2B: Derived geophysical parameters - Analysis products; Level 3: Zonal mean and mapped geophysical parameters produced using daily, weekly, monthly, and seasonally averaged data; and Level 4: Model derived products developed for example, from more than one measurement. SABER data are retrieved on pressure surfaces and tied to altitude through registration within collocated NCEP temperature, pressure, and altitude profiles merged into the SABER data stream on the ground. Level 1B products will include tangent altitude and pressure versus radiance for selected spectral bands: $\mathrm{CO}_{2}\left(\mathrm{v}_{2}\right)$ centered at 14.9 and $15.0 \mu \mathrm{m}$ and $\mathrm{O}_{3}\left(v_{3}\right)$ at $9.3 \mu \mathrm{m}, \mathrm{H}_{2} \mathrm{O}\left(\mathrm{v}_{2}\right)$ at $6.8 \mu \mathrm{m}, \mathrm{NO}(v)$ at $5.3 \mu \mathrm{m}, \mathrm{CO}_{2}\left(\mathrm{v}_{3}\right)$ at $4.2 \mu \mathrm{m}, \mathrm{OH}(\mathrm{v}=7,8,9)$ at $2.06 \mu \mathrm{m}, \mathrm{OH}(v=3,4,5)$ at $1.6 \mu \mathrm{m}$, and $\mathrm{O}_{2}\left({ }^{1} \Delta\right)$ at $1.27 \mu \mathrm{m}$. Level $2 \mathrm{~A}$ and Level 2B products are described in Tables 2 and 3. Other SABER Level 2B products not listed in Table 3 are: 1) Solar heating rates in the 20 to $100 \mathrm{~km}$ altitude range due to $\mathrm{O}_{3}$ in the Hartley, Huggins, and Chappius bands; $\mathrm{O}_{2}$ in the Schumann-Runge, Ly- $\alpha$, Herzberg, and atmospheric bands, and $\mathrm{CO}_{2}$ at $4.3 \mu \mathrm{m} ; 2$ ) Chemical heating rates from 80 to $100 \mathrm{~km}$ due to the $\mathrm{O}_{x}$ and $\mathrm{HO}_{x}$ families; and 3) Airglow and chemiliminescent, emission/heating efficiency due to $\mathrm{O}_{2}\left({ }^{1} \Delta\right)$ from 50 to $105 \mathrm{~km}$ and $\mathrm{OH}(1.6 \mu \mathrm{m}$ and $2.0 \mu \mathrm{m})$ from 80 to $100 \mathrm{~km}$. A LIMS experiment pressure versus temperature profile is shown in Fig. 5 as an example of a routine product. SABER will make measurements to much higher altitudes than LIMS (e.g. for $\mathrm{Z}>100 \mathrm{~km}$ ). A HALOE experiment pressure versus latitude sunset water vapor cross section is shown in Fig. 6 as an example of a SABER Level 3 product. The estimated accuracy and precision for the Level $2 \mathrm{~A}$ products are given in Table 4.

\section{Geographic Coverage}

Typical SABER daily latitude versus longitude coverage is shown in Fig. 7 below for a May 18, 2000 launch. SABER will always view on the anti-Sun side of the spacecraft resulting in asymmetric global coverage during any 60 day period as shown in Fig. 8. Coverage of opposite poles occurs as the spacecraft periodically yaws. The time of year when SABER observes the summer polar region can be selected by changing the initial equatorial crossing time.

Table 2. SABER Level 2A Routine Products (Day and Night)

\begin{tabular}{|c|c|}
\hline Parameter & Range \\
\hline Kinetic T, P, density & $10-105 \mathrm{~km}$ \\
\hline Altitude & $10-200 \mathrm{~km}$ \\
\hline $\mathrm{O}_{3}$ mixing ratio $(9.6 \mu \mathrm{m})$ & $15-100 \mathrm{~km}$ \\
\hline $\mathrm{O}_{3}$ mixing ratio $(1.27 \mu \mathrm{m})^{* *}$ & $50-95 \mathrm{~km}$ \\
\hline $\mathrm{H}_{2} \mathrm{O}$ mixing ratio & $15-80 \mathrm{~km}$ \\
\hline NO $5.3 \mu \mathrm{m}$ VER $^{*}$ & $100-180 \mathrm{~km}$ \\
\hline $\mathrm{OH} 1.6 \mu \mathrm{m}$ VER $^{*}$ & $80-100 \mathrm{~km}$ \\
\hline $\mathrm{OH} 2.0 \mu \mathrm{m}$ VER ${ }^{*}$ & $80-100 \mathrm{~km}$ \\
\hline $\mathrm{O}_{2}\left({ }^{1} \Delta\right) 1.27 \mu \mathrm{m}$ VER $^{*}$ & $50-105 \mathrm{~km}$ \\
\hline
\end{tabular}

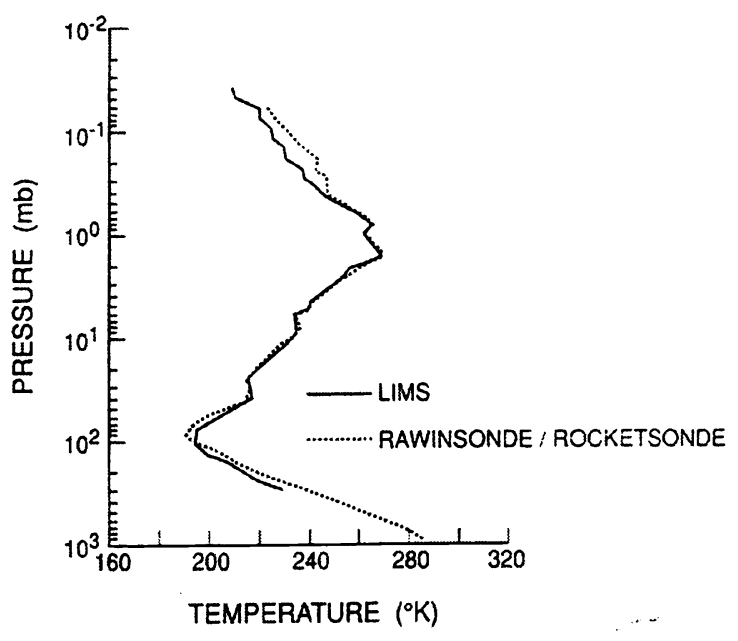

Fig. 5. Level 2 data product example from LIMS 
Table 3. SABER Level 2B Analysis Products (Day and Night)

\begin{tabular}{|c|c|}
\hline Parameter & Range \\
\hline \multicolumn{2}{|l|}{ Temperature \& Constituents } \\
\hline Kinetic $\mathrm{T}, \mathrm{P}$, density & $\mathrm{Z} \geq 105 \mathrm{~km}$ \\
\hline $\mathrm{CO}_{2}(4.3 \mu \mathrm{m})$ density ${ }^{*}$ & $85-160 \mathrm{~km}$ \\
\hline \multicolumn{2}{|l|}{ [O] concentration } \\
\hline - $\mathrm{O}_{3}$ day / night $\Delta \mathrm{s}^{*}$ & $60-80 \mathrm{~km}$ \\
\hline - $\mathrm{O}_{2}\left({ }^{1} \Delta\right)$ nightglow & $80-100 \mathrm{~km}$ \\
\hline - $\mathrm{O}_{3}(9.6 \mu \mathrm{m}) / \mathrm{OH}(2.0 \mu \mathrm{m})$ & $80-100 \mathrm{~km}$ \\
\hline$-\mathrm{CO}_{2}(4.3 \mu \mathrm{m}) / \mathrm{CO}_{2}(15 \mu \mathrm{m})^{*}$ & $100-135 \mathrm{~km}$ \\
\hline [H] Concentration & $80-100 \mathrm{~km}$ \\
\hline Geostrophic Wind & $20-100 \mathrm{~km}$ \\
\hline \multicolumn{2}{|l|}{ Cooling Rates } \\
\hline $\mathrm{CO}_{2}(15 \mu \mathrm{m})$ & $20-140 \mathrm{~km}$ \\
\hline $\mathrm{NO}(5.3 \mu \mathrm{m})$ & $100-180 \mathrm{~km}$ \\
\hline $\mathrm{O}_{3}(9.6 \mu \mathrm{m})$ & $20-100 \mathrm{~km}$ \\
\hline $\mathrm{H}_{2} \mathrm{O}(6.7 \mu \mathrm{m}$ and far IR $)$ & $20-70 \mathrm{~km}$ \\
\hline
\end{tabular}

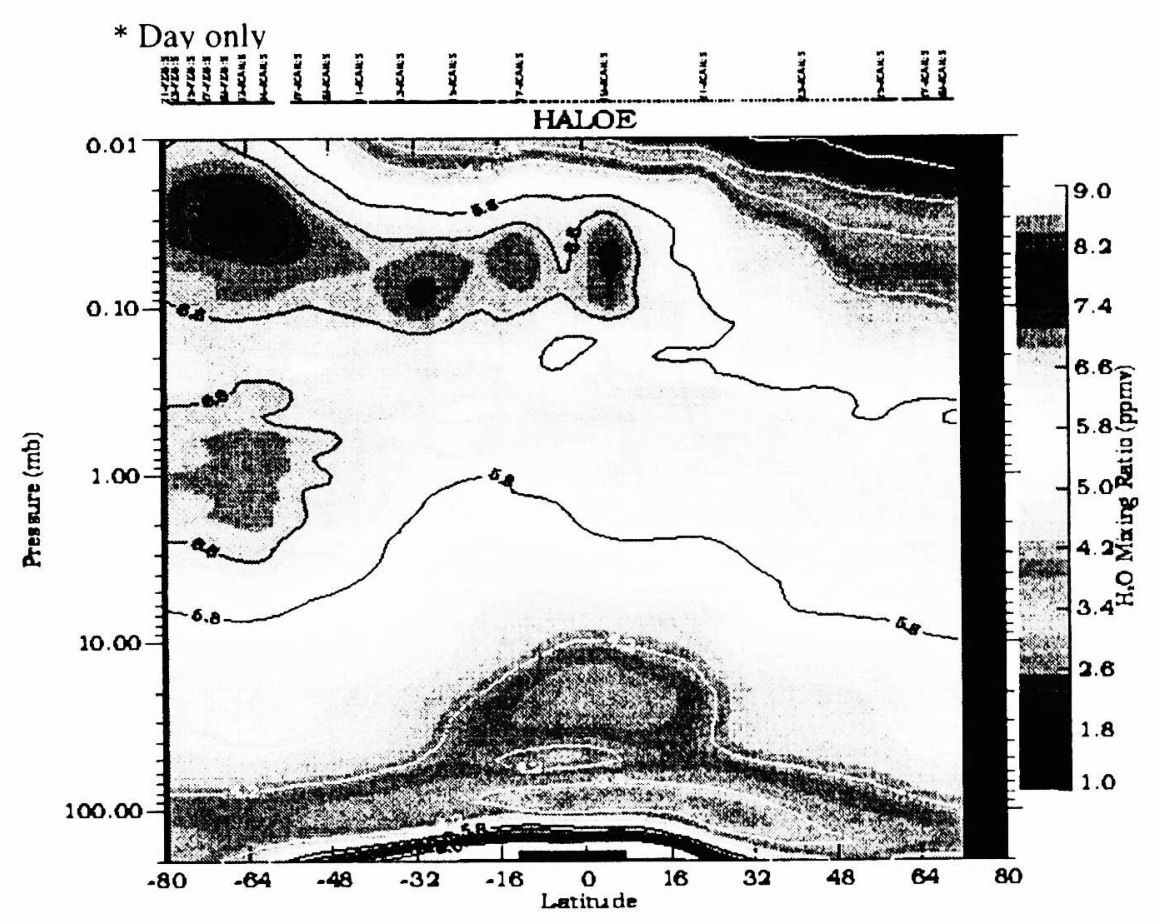

Fig. 6. Level $3 \mathrm{H}_{2} \mathrm{O}$ data product example from HALOE 
Table 4. Temperature and Constituent Estimated Accuracies and Precisions

\begin{tabular}{|c|c|c|c|}
\hline Parameter & $\begin{array}{c}\text { Measurement } \\
\text { Range } \\
\end{array}$ & Accuracy & Precision \\
\hline Temperature & $10-130 \mathrm{~km}$ & $\begin{array}{l}1.0 \mathrm{~K}, 10-65 \mathrm{~km} \\
1.5 \mathrm{~K}, 65-80 \mathrm{~km} \\
\end{array}$ & $\begin{array}{l}<0.3 \mathrm{~K}, 10-70 \mathrm{~km} \\
<0.7 \mathrm{~K}, 70-80 \mathrm{~km}\end{array}$ \\
\hline $\mathrm{O}_{3}($ from $9.6 \mu \mathrm{m})$ & $10-100 \mathrm{~km}$ & $\begin{array}{l}10 \%, 10-65 \mathrm{~km}^{*} \\
20 \%, 65-80 \mathrm{~km} *\end{array}$ & $\begin{array}{l}2 \%, 10-65 \mathrm{~km} \\
5 \%, 65-80 \mathrm{~km} \\
\end{array}$ \\
\hline $\begin{array}{l}\mathrm{O}_{3}[\text { from } \\
\left.\mathrm{O}_{2}\left({ }^{1} \Delta\right)\right]^{* *}\end{array}$ & $50-95 \mathrm{~km}$ & $20 \%, 50-95 \mathrm{~km} * *$ & $\begin{array}{c}5 \%, 50-85 \mathrm{~km} \\
15 \%, 85-95 \mathrm{~km}\end{array}$ \\
\hline $\mathrm{H}_{2} \mathrm{O}$ & $10-80 \mathrm{~km}$ & $\begin{array}{l}15 \%, 10-65 \mathrm{~km} \\
25 \%, 65-80 \mathrm{~km}\end{array}$ & $\begin{array}{l}4 \%, 10-65 \mathrm{~km} \\
7 \%, 65-80 \mathrm{~km}\end{array}$ \\
\hline NO \# & $90-180 \mathrm{~km}$ & $30 \%, 90-150 \mathrm{~km} \#$ & $10 \%, 90-150 \mathrm{~km}$ \\
\hline $\mathrm{CO}_{2} \#$ & $85-150 \mathrm{~km}$ & $30 \%, 95-140 \mathrm{~km}$ \#\# & $10 \%, 95-140 \mathrm{~km}$ \\
\hline
\end{tabular}

* Nighttime accuracy estimates. Daytime accuracy degrades due to Non-LTE

** Daytime measurement only. Under twilight conditions accuracy degrades due to difference in chemical lifetime of $\mathrm{O}_{3}$ and radiative lifetime of $\mathrm{O}_{2}\left({ }^{1} \Delta\right)$

\# Assumes [O] is known to $25 \%$ accuracy

\# Daytime measurement only

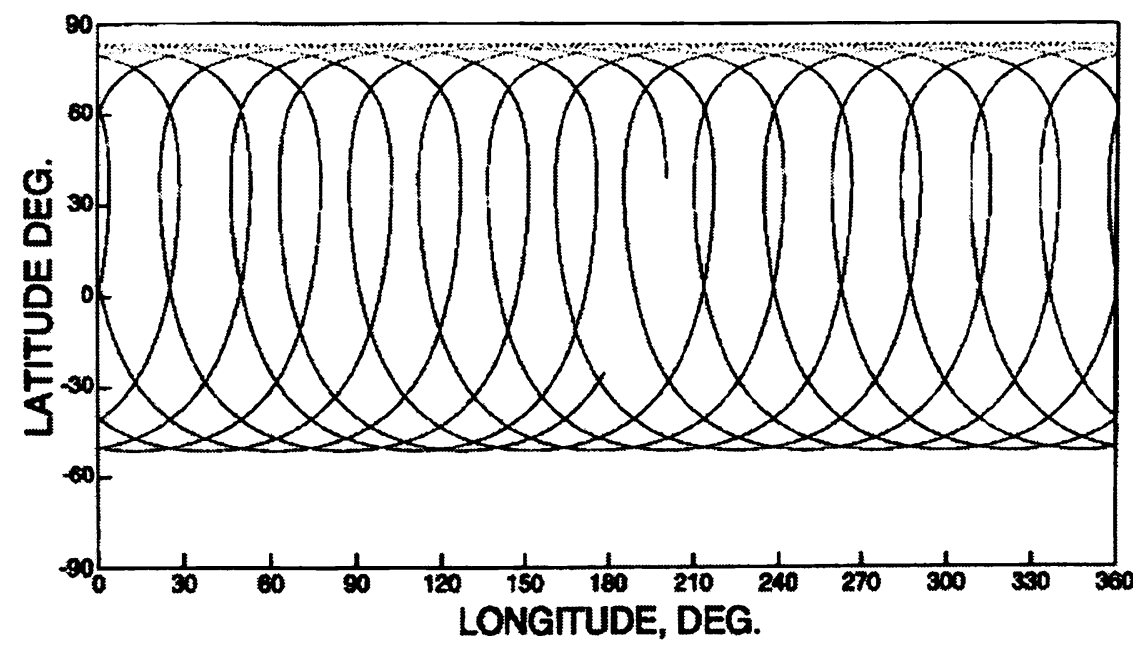

Fig. 7 SABER daily latitude versus longitude coverage ( $83 \mathrm{~N}$ to $52 \mathrm{~S}$ ) for a North viewing phase of the spacecraft yaw cycle. 


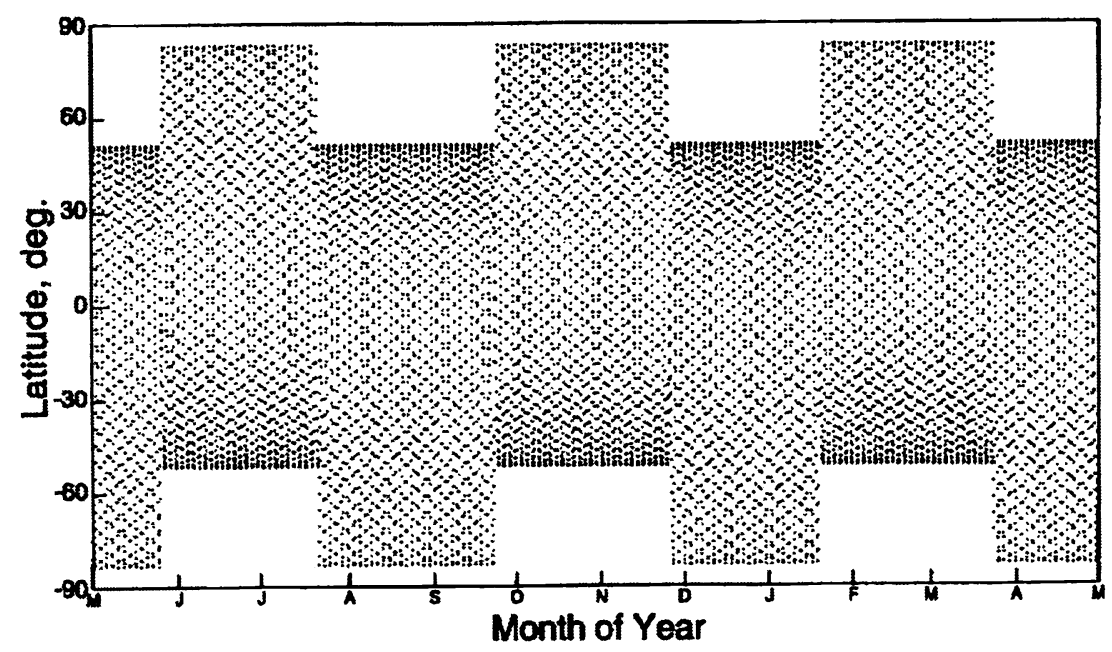

Fig. 8 SABER latitude coverage versus time of year based on a May 18, 2000 launch into a 74.06 degree inclined orbit with an initial equatorial crossing time of 18:00. This crossing gives Northern polar coverage nearly centered around the summer solstice.

\section{PRELIMINARY TEST AND CALIBRATION RESULTS}

The SABER instrument is in the final stages of pre-flight testing and calibration in preparation for delivery to the spacecraft for integration. In order to maximize efficiency of this process, a preliminary engineering calibration was performed to exercise all the major procedures and to attempt to uncover early on, any issues in the test setups or instrument that may need to be addressed during the final calibration. The first test performed was to determine the capability of the instrument to reject off-axis energy. This is especially important because SABER uses a Cassegrain telescope design which typically is not optimal for stray light rejection. Additionally, the three short wavelength channels $(1.27 \mu \mathrm{m}, 1.6 \mu \mathrm{m}$, and $2.1 \mu \mathrm{m})$ are highly susceptible to contamination by scattered sunlight off clouds and the Earth below, which when viewed directly, is many orders of magnitude higher than the radiometric signal observed in the mesosphere. The initial tests were performed on the telescope and relay optics subassembly in a special "Black Hole" test setup at the SDL. These tests showed excellent response with the off-axis signal being down by 6 orders of magnitude and higher at $3^{\circ}$ and larger angles off-axis. By curve fitting and extrapolation, we infer that the rejection is 5 orders at $1^{\circ}$ and 6 orders at $2^{\circ}$ off axis. After all SABER subassemblies were fully integrated, a series of calibration tests were performed on the instrument including tests to determine the instantaneous vertical field-of-view (IFOV); off-axis rejection characteristics; temporal response; end-to-end spectral response measured both in-band and out-of-band; and lastly, a preliminary primary radiometric calibration to examine system linearity and stability.

\subsection{IFOV}

Two sets of scans were performed to determine the IFOV. One was done with the SABER scan mirror moving at the nominal rate of $0.21 \% \mathrm{sec}$ and a second set with the mirror moving at only $25 \%$ of the nominal rate. The slow scan was done to essentially eliminate the electronics time and phase lag as parameters in the measurement. The nominal scan was done to obtain the information in the actual flight mode. An example of the IFOV results is shown in Fig. 9 for one of the two $\mathrm{CO}_{2}$ $15.0 \mu \mathrm{m}$ channels. The curve with the large feature peaking at about 3825 counts is a background scan which, after subtraction yields the true IFOV response function with the flat off-axis curve. This large background signal has been traced to the test setup and will be minimized in the final calibration. The IFOV full width at half maximum for all channels meets specifications of $\sim 0.7 \mathrm{mr}$ or $\sim 2 \mathrm{~km}$ at the tangent point for the $625 \mathrm{~km}$ nominal orbit altitude.

\section{2 “Knife Edge” Scans}

The next spatial response test was performed by causing the SABER mirror to scan across a warm knife edge target to simulate in as far as possible, the actual measurement environment of scanning from cold space down to the hard, warm 
extended source (as opposed to a point source) Earth. The purpose of this test was to examine the near angle $\left(\leq \sim 5^{\circ}\right.$ ) stray light rejection characteristics. The results of this test are shown in Fig. 10. Note that the vertical axis is a log scale and that for all channels, the signals are very flat after passing off the knife edge indicating very small off-axis signal. Signals drop by orders of magnitude in $3^{\circ}$ off the knife edge. It is believed that the test setup limited ability to determine off-axis rejection to 5 orders. These results for the fully integrated instrument show excellent stray light rejection.

\subsection{Temporal Response}

A four pole Butterworth electronics filter governs the SABER temporal response. The effects of the filter need to be carefully determined so that amplitude and phase distortions that occur as SABER scans across atmospheric features on the horizon can be removed. The electronics system transfer function was measured by injecting a voltage step function at the detector preamplifier input and sampling the signal at the AVD input at a $500 \mathrm{~Hz}$ rate. This provided detailed characterization of the frequency response function. Note that the nominal SABER sampling rate at the A/D output is $22.73 \mathrm{~Hz}$. The full end-to-end SABER temporal response was measured by shuttering a radiometric source illuminating the entrance aperture to create a step function in radiance. Results of this test are shown in Fig. 11. The expected overshoot, undershoot, settling time and phase lag are seen in the unprocessed data. The smooth curve was obtained by applying the electronics time domain transfer function to the output data to demonstrate the ability to remove phase and amplitude distortions.

\subsection{End-to-End Spectral Response}

The end-to-end spectral response was measured using a radiometric source/interferometer system for both in-band and outof-band regions for all channels and at three detector/filter focal plane temperatures $(72 \mathrm{~K}, 75 \mathrm{~K}$, and $80 \mathrm{~K})$. The $5 \%$ cut-on and cut-off points are within specifications for all channels. The out-of-band response specification of $\sim 10^{-4}$ was met in all channels except the $14.9 \mu \mathrm{m}$ narrow band $\mathrm{CO}_{2}$ where it is $5 \times 10^{-4}$. This higher value occurred at the longest wavelength for the test setup of about $25 \mu \mathrm{m}$ and is believed to be due to degrading test setup $\mathrm{S} / \mathrm{N}$ and not real out-of-band response. Further data analysis is underway.

\subsection{Primary Radiometric Calibration and Noise Equivalent Radiance}

The engineering calibration included only a subset of the primary radiometric calibration measurements planned for the final series of tests now in progress. Two blackbody sources were used, termed the low temperature blackbody (LTBB) and high temperature blackbody (HTBB). These sources operated over the temperature ranges of $100 \mathrm{~K}$ to 350 and $350 \mathrm{~K}$ to $710 \mathrm{~K}$ for the LTBB and HTBB respectively. The HTBB was needed to stimulate the short wavelength channels to their maximum expected levels in orbit for the condition of cloud scattered sunlight entering the instrument aperture. Measurements were made at only a subset of radiometric source temperatures and one instrument baseplate temperature. The results of this test for the $\mathrm{CO}_{2} \mathrm{~N}$ channel, as an example, are shown in Fig. 12. The deviation from linearity in this channel, which is typical, is on the order of a fraction of a percent. During the course of these tests, the preliminary noise-equivalent-radiances (NER) were also determined. The achieved performance is slightly worse than specifications (1.5 times) in the $\mathrm{CO}_{2} \mathrm{~N}$ channel, equal to the specifications for the two $\mathrm{CO}_{2}$ W channels, 2 times better for $\mathrm{H}_{2} \mathrm{O}, 3$ times better for $\mathrm{O}_{3}$, the two $\mathrm{OH}$, and $\mathrm{O}_{2}\left({ }^{1} \Delta\right)$ channels, and about 20 times better for $\mathrm{NO}$ and $\mathrm{CO}_{2} 4.3 \mu \mathrm{m}$. This performance will allow the highest altitude measurement goals of SABER to be exceeded.

\section{SUMMARY}

The SABER experiment uses the space flight proven instrument and measurement approaches of broadband radiometry and limb emission sounding to study the mesosphere and lower thermosphere. The experiment is based on a rich heritage of past limb sounding applications and the instrument design draws heavily on the highly successful LIMS experiment flown on the Nimbus 7 satellite. SABER will provide measurements of temperature, constituents, and key energetics emissions throughout much of the TIMED core region from $60 \mathrm{~km}$ to $180 \mathrm{~km}$ altitude. The experiment is the first application of an infrared emission experiment dedicated and designed to measure important energetics, chemistry, and dynamics parameters on a global scale in this important region of our atmosphere which up to now has been largely unexplored. The initial tests and engineering calibration show excellent performance with the NER of the instrument exceeding specifications by up to 20 times in some channels. 


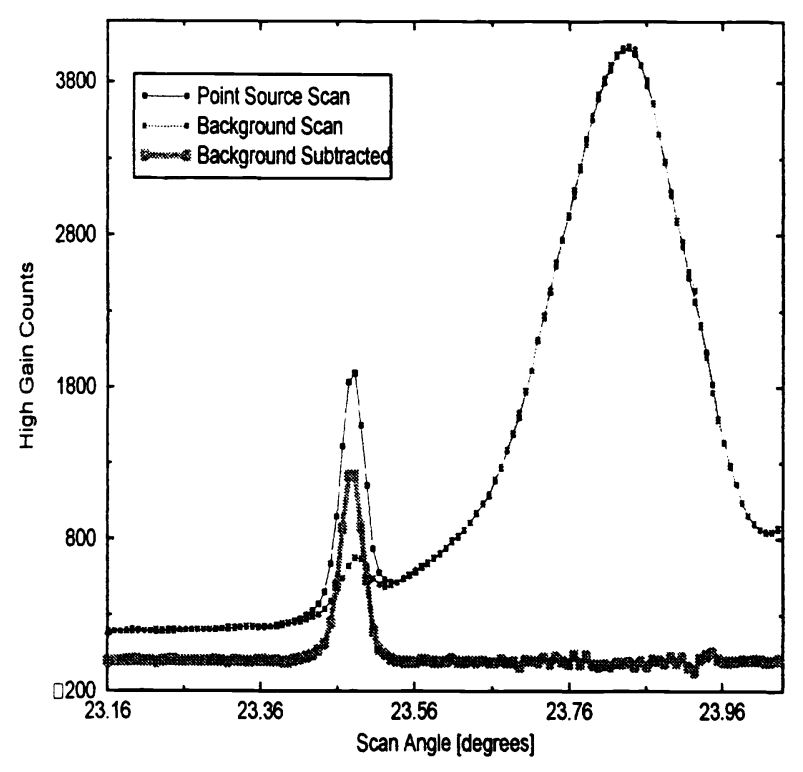

Fig. $9 \mathrm{SABER} \mathrm{CO}_{2} \mathrm{~W}$ point source scan, background scan, and IFOV.

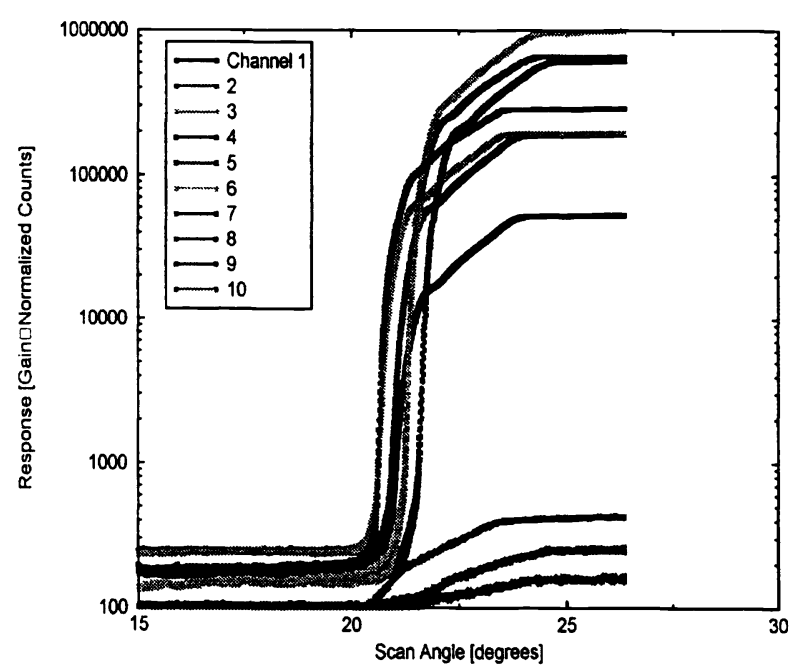

Fig. 10. SABER "Knife edge" scan showing near angle off-axis rejection in all channels.

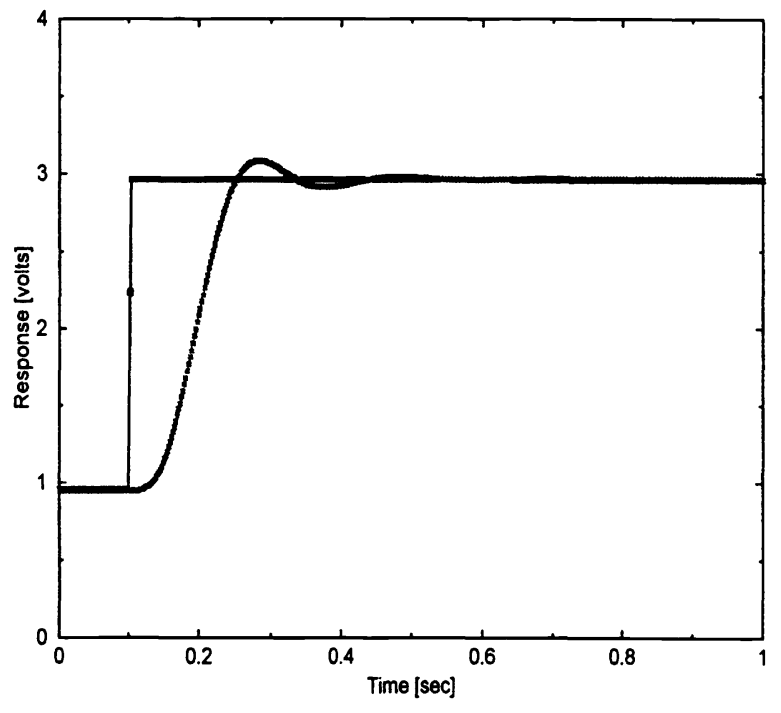

Fig. $11 \mathrm{SABER} \mathrm{CO}_{2} \mathrm{~N}$ Radiometric step function response and response with electronic filter effects removed.

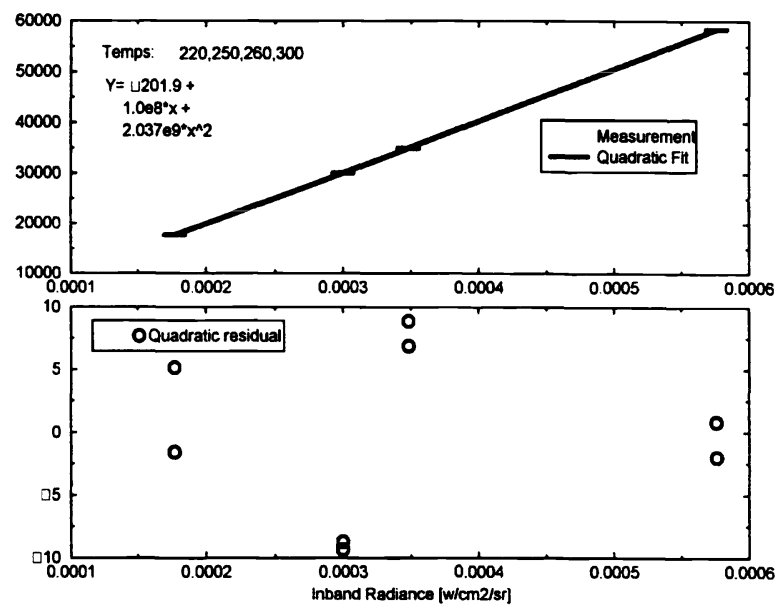

Fig. $12 \mathrm{SABER} \mathrm{CO}_{2} \mathrm{~W}$ preliminary radiometric calibration. 


\section{REFERENCES}

1. Russell, J. M. III, M.G. Mlynczak, and L.L. Gordley, An overview of the SABER experiment for the TIMED mission, SPIE Proceedings 2266, Optical Techniques and Instrumentation for Atmospheric and Space Research, Jinxue Wang and Paul B. Hayes, Eds., pages 406-414, 1994.

2. Mlynczak, M. G. and Russell, J. M. III, An overview of the SABER experiement for the TIMED mission, Optical Remote Sensing of the Atmosphere, 2, OSA Technical digest Series, Washington, D.C., pages 5-7, 1995.

3. Russell, J. M. III, and J. C. Gille, The Limb Infrared Monitor of the Stratosphere (LIMS) experiment in Ihe Nimbus 7 User's Guide, edited by C. R. Madrid, 71-103, NASA Goddard Space Flight Center, Greenbelt, MD, 1978.

4. Gille, J. C., and J. M. Russell III, The Limb Infrared Monitor of the Stratosphere: Experiment description, performance, and results, I. Geophys. Res., 89, 5125-5140, 1984.

5. Mlynczak, M.G., D.S. Olander, and M. Lopez-Puertas, Rapid computation of spectrally integrated non-local thermodynamic equilibrium limb emission, J. Geophys. Res., Vol. 99, No. D12, pages 25,761-25,772, December 20, 1994.

6. Mlynczak, Martin G., Susan Solomon, and Daphne S. Zaras, An updated model for $\mathrm{O}_{2}\left(\mathrm{a}^{1} \Delta_{\mathrm{g}}\right)$ concentrations in the mesosphere and lower thermosphere and implications for remote sensing of ozone at $1.27 \mu \mathrm{m}, \mathrm{J}$. Geophys. Res., Vol. 98, No. D10, October 20, 1993.

7. Mlynczak, Martin G and Daphne S. Olander, On the utility of the molecular ozygen dayglow emissions as proxies for middle atmospheric ozone, Geophys. Res. Lett., Vol. 22, No. 11, pages 1377-1380, June 1, 1995.

8. Mlynczak, Martin G. and D.S. Zhou, Kinetic and spectroscopic requirements for the measurementof mesospheric ozone at $9.6 \mu \mathrm{m}$ under non-LTE conditions, Geophys. Res. Lett., Vol. 25, pages $639-642,1998$.

9. Mlynczak, M. G., D. K. Zhou, M. Lopez-Puertas, G. Zaragoza and J. M. Russell III, Kinetic requirements for the measurement of mesospheric water vapor at $6.8 \mu \mathrm{m}$ under non-LTE conditions, Geophys. Res. Lett., 26, NO. 1, 6366, January 1, 1999.

10. Mlynczak, Martin G., D.S. Zhou, and S.M.Adler-Golden, Kinetic and spectroscopic requirements for the inference of chemical heating rates and atomic hydrogen densities from $\mathrm{OH}$ Meinel band measurements, Geophys. Res. Lett., Vol. 25, pp. 647-650, 1998.

11. Zhou, D. K., M. G. Mlynczak, M. Lopez-Puertas, and G. Zaragoza, Evidence of non-LTE effects on the mesospheric water vapor observed by spectrally resolved transitional-emissions from CIRRIS-1A, Geophys. Res. Lett., Vol. 26, pages $63-66,1999$.

12. Mlynczak, M. G., Energetics of the mesosphere and lower thermosphere and the SABER experiment, Adv. Space. Res., Vol. 20, pages $1177-1183,1997$.

13. Mlynczak, M. G., A new perspective on the molecular oxygen and hydroxyl airglow emissions, Accepted by $\underline{\mathrm{J}}$. Geophys. Res., July, 1999.

14. Esplin, Roy, L. Zollinger, C. Batty, S. Folkman, M. Roosta., J. Tansock, M. Jensen, J. Stauder, J. Miller, M. Vanek, and D. Robinson, SABER instrument design update, SPIE Proceedings Vol. 2553. 